\title{
$\mathrm{HEVC}$ 부호화를 위한 변환생략 모드 고속 선택 방법
}

\author{
양 승 하*, 심 혁 재", 이 다 희", 전 병 우
}

\section{Transform Skip Mode Fast Decision Method for HEVC Encoding}

\author{
Seungha Yang*, Hiuk Jae Shim*, Dahee Lee*, Byeungwoo Jeon \\ 요 약
}

HEVC (High Efficiency Video Coding) 부호화 기술은 기존 기술을 더욱 정교하게 하고 많은 새로운 부호화 기법을 채택한 결과, 기존 비디오 부호화 표준인 H.264/AVC 대비 약 2배정도 압축률 향상을 이루었다. HEVC에 채택된 새로운 부호화 기술 중 하나인 변환을 생략하고 양자화만을 수행하는 변환생략 부호화 방법은, 특히 컴퓨 터로 생성된 인공영상 또는 이와 유사한 성질을 갖는 영상영역의 부호화 시 큰 압축률 향상을 가져올 수 있다. 하지만 입력 영상의 전체 또는 국부적인 성질을 미리 알 수 없기 때문에, 변환생략 필요 여부를 매번 판별하여야 한다. 즉, 변환수행 혹은 변환생략 각 경우의 율-왜곡 비용을 산출하여 부호화모드를 결정하려면 연산복잡도가 증 가한다. 본 논문에서는 잔차신호의 주파수적 특성을 고려하여, 변환생략의 율-왜곡 산출 여부에 대한 고속 판별 방 법을 제안한다. 제안 방법을 적용할 경우, $4 \times 4$ 변환 블록 부호화 시간의 약 $27.1 \%$ 를 절감할 수 있으며, 이때 저 하되는 율-왜곡 성능은 평균적으로 약 $0.03 \%$ (BDBR)에 불과하다.

Key Words : HEVC, Residual Coding, Transform, Transform Skip

\section{ABSTRACT}

HEVC (High Efficiency Video Coding) fine-tuned many existing coding tools and adopted also many new coding techniques. As a result, HEVC has accomplished about 2 times of compression efficiency enhancement compared to the existing video coding standard of H.264/AVC. One of the newly adopted tools in HEVC is the transform skip scheme which performs quantization without transform. This technique improves coding efficiency especially with computer-generated images. However, the unavailability of global or local properties of general video signals demands encoder to decide whether performing transform or not for each TU (Transform Unit). The necessity of computing rate-distortion costs for this decision is one reason to increase encoder complexity. In this paper, a fast transform skip mode decision method is proposed, which is based on the fast decision of rate-distortion cost calculation for transform skip mode, by considering frequency characteristics of residual signal. The proposed method can reduce $4 \times 4$ TU encoding time by about $27.1 \%$ with only about $0.03 \%$ consequential decrement in BDBR.

※ 이 논문은 삼성전자 2013년도 S.LSI 사업부 및 2011년도 정부(미래창조과학부)의 재원으로 한국연구재단의 지원을 받아 수행된 연 구임(No. 2011-001-7578)

- First Author : Sungkyunkwan Univ. School of Electronic and Electrical Engineering, pudding@skku.edu, 학생회원

- Corresponding Author : Sungkyunkwan Univ. School of Electronic and Electrical Engineering, bjeon@skku.edu, 종신회원

* Sungkyunkwan Univ. School of Electronic and Electrical Engineering, \{waitnual, dadi0413\} @skku.edu, 정회원, 학생회원 논문번호: KICS2014-03-076, Received March 5, 2014; Revised March 24, 2014; Accepted March 24, 2014 


\section{I. 서 론}

HEVC (High Efficiency Video Coding) ${ }^{[1]}$ 는 기존 H.264/AVC ${ }^{[2]}$ 대비 동일 품질에서 약 2배 이상의 압 축률 향상을 목표로, 국제 표준화 기구인 ITU-T와 $\mathrm{ISO} / \mathrm{IEC}$ 가 공동으로 설립한 전문가 그룹인 JCT-VC (Joint Collaborative Team on Video Coding) 에 의 해 개발된 비디오 부호화 표준이다. 이 표준의 주요 목적은 고해상도 HD (High Definition) 영상을 넘어 선 초고해상도 UHD (Ultra High Definition) 영상의 효율적인 부호화이다. HEVC는 CU (Coding Unit) / PU (Prediction Unit) / TU (Transform Unit) 와 같은 다양한 크기의 블록 분할구조와 같이 기존 개념을 더 욱 유연하고 정교하게 만든 기술뿐만 아니라, $\mathrm{SAO}$ (Sample Adaptive Offset) 또는 변환생략 (transform skip) ${ }^{[3,4]}$ 등과 같은 새로운 부호화 기법들도 채택하였 다. $\mathrm{HEVC}$ 이전의 기존 표준들이 스크린 콘텐츠 (Screen Content)와 같은 자연 영상외의 인공영상들의 효율적인 부호화를 별로 고려하지 않아 왔던 것과는 다르게, $\mathrm{HEVC}$ 버전 1 표준은 스크린 콘텐츠의 부호 화 시 압축률 향상 효과가 크다는 장점이 알려진 변환 생략 기술을 새롭게 채택하였다. 이때 변환생략 기술 은 $4 \times 4$ 크기의 $\mathrm{TU}$ 에서만 사용된다. $\mathrm{HEVC}$ 버전 1 을 이은 확장기술로 현재 표준화가 진행 중인 $\mathrm{HEVC}$ Range Extension ${ }^{[5]}$ 이 스크린 콘텐츠를 주요 부호화 대상 영상 중 하나로 포함시킨 것으로 미루어 볼 때, 스크린 콘텐츠 부호화의 중요성이 나날이 증가되고 있음을 볼 수 있다. 스크린 콘텐츠란 컴퓨터로 생성된 컴퓨터 그래픽, 그래프, 텍스트 등을 포함하고 있는 인공적인 영상을 의미하며 카메라로 촬영된 지금까지 의 자연 영상과는 다른 특성을 가진다. 일반적으로, 스크린 콘텐츠 영상은 상당히 강한 엣지 성분을 포함 하고 있어, 자연 영상에서는 발생 확률이 비교적 낮은 고주파 성분을 많이 포함하고 있는 것이 특징이다. 또 한, 예측을 통해 생성된 잔차신호 또한 고주파 성분을 많이 포함한다. 이러한 특성 때문에, DCT (discrete cosine transform) ${ }^{[6]}$ 또는 DST (discrete sine transform) ${ }^{[6]}$ 와 같은 변환을 수행하여도 에너지의 집 중 효과가 적을뿐더러 변환을 취하는 것이 오히려, 부 호화 효율 면에서 불리한 경우가 많이 있다. 따라서 $\mathrm{HEVC}$ 표준은, $4 \times 4 \mathrm{TU}$ 에 대하여 변환을 수행하는 것이 오히려 압축 효율을 저하시키는 경우에는 변환 을 생략하고 양자화만을 수행할 수 있도록 하는 변환 생략 모드를 기존의 부호화 방식에 추가하였다. 따라 서, 더욱 향상된 부호화 효율을 얻으려면, 부호화기는
매 $4 \times 4 \mathrm{TU}$ 단위로 기존처럼 변환을 수행하여 부호 화할지 (이하 변환 모드 (transform mode)라고 부르 자), 또는 변환을 생략하여 부호화 할지 (이하 변환생 략 모드 (transform skip mode)라고 하자) 여부를 결 정하여야 하므로 이와 같은 결정을 위하여 부호화기 의 연산을 추가로 필요로 하는 문제점이 발생한다. 본 논문에서는 이를 해결하고자 잔차신호의 특성을 고려 하여 변환생략 모드가 최종 선택되는 경우의 특성을 분석하고 이를 기반으로 효율적으로 변환생략 모드를 선택하는 방법을 제안한다.

본 논문의 구성은 다음과 같다. 우선 2장에서는 $\mathrm{HEVC}$ 의 TU 분할 구조와 변환생략 모드 결정 방법을 살펴본다. 3장에서는 변환생략 모드의 통계적 특성을 분석하고 제안하는 변환생략 모드 고속 선택 방법에 대하여 설명한다. 4장에서는 실험결과를 통해 제안 방 법의 성능을 평가하고, 마지막으로 5장에서는 결론을 내린다.

\section{HEVC의 변환생략 모드}

\subsection{HEVC의 TU 분할 구조}

$\mathrm{HEVC}$ 는 (화면 내 또는 화면 간) 예측 신호와 원본 신호의 차이인 잔차신호에 대하여 TU 단위로 변환 및 양자화를 수행한다. TU는 변환 및 양자화를 수행하는 기본 단위로서 각 TU별로 현재 TU와 동일 크기의 변 환을 수행하며, 이때 TU가 가질 수 있는 크기는 최대 $32 \times 32$ 부터 $16 \times 16,8 \times 8$, 그리고 최소 $4 \times 4$ 까지 이다. 각 TU들은 DCT 기반의 변환을 수행하지만, 예 외적으로 화면 내 예측을 수행한 $4 \times 4 \mathrm{TU}$ 의 경우 DST 기반의 변환을 수행한다. 잔차신호는 그림 1 과 같이 RQT (Residual Quad-Tree) 구조로 이루어진

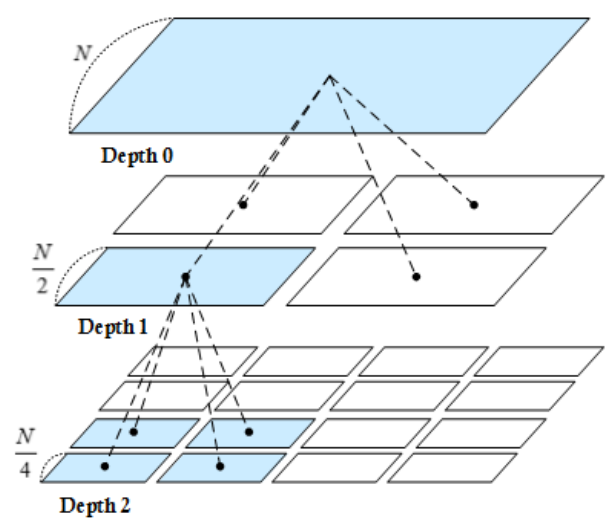

그림 1. $\mathrm{HEVC}$ 의 $\mathrm{RQT}$ 구조

Fig. 1. RQT structure of HEVC. 
$\mathrm{TU}$ 들로 분할된다. 이때 분할되지 않은 잔차신호 블록 에 해당하는 깊이를 depth 0 이라 하고, 이를 기준으 로 $\mathrm{TU}$ 는 최대 3 단계의 깊이 (즉 depth $0,1,2$ )를 가 질 수 있다. 여기서, depth 0 은 $\mathrm{HEVC}$ 의 부호화의 기 본 단위인 $\mathrm{CU}$ 에 해당한다. 부호화기는 depth 0 부터 최대 depth 2 까지 가능한 모든 TU들의 조합에 대하여 율-왜곡 비용을 산출하고 이를 기반으로 최적의 $\mathrm{TU}$ 분할 조합을 선택한다.

\section{$2.2 \mathrm{HM}$ 의 변환생략 모드 결정 방법}

$\mathrm{HEVC}$ 버전 1 기술에 따르면, 화면 내 (Intra) 예측 과 화면 간 (Inter) 예측 모두 $4 \times 4 \mathrm{TU}$ 에 한정하여 변환생략 모드를 지원한다. 그림 2 와 같이 $\mathrm{HEVC}$ 참 조 소프트웨어인 $\mathrm{HM}$ 의 부호화기는 $4 \times 4 \mathrm{TU}$ 모드 결정을 위하여 변환 모드와 변환생략 모드 각각에 대 한 율-왜곡 비용을 산출하여 비교한다. 한편, 변환 및 양자화를 수행한 이후 대부분의 변환계수가 0 이라면, 모든 변환계수를 0 으로 간주하여 전송에 소요되는 비 트량을 절약하는 것이 율-왜곡 효율측면에서 이득일 수 있다. 이러한 경우까지 고려하기 위하여 그림 2에 점선으로 표시된 과정에서 화면 간 예측 부호화 시 $\mathrm{CBF}$ (coded block flag)를 강제로 0으로 설정할 경우 의 율-왜곡 비용까지 추가로 산출한 후, 이를 변환 모 드와 변환생략 모드와 함께 비교한다. $\mathrm{CBF}$ 는 양자화 후 TU 내 0이 아닌 신호의 존재여부를 표시한 플래그

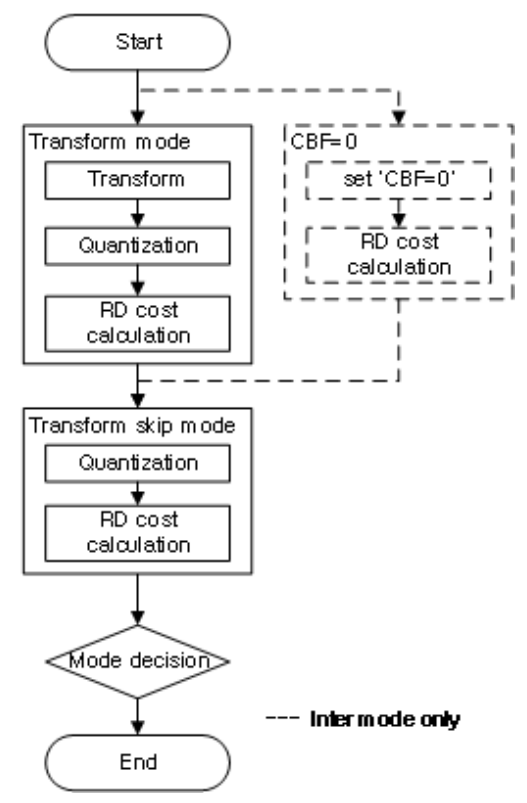

그림 2. $\mathrm{HM}$ 의 $4 \times 4 \mathrm{TU}$ 모드 결정 과정

Fig. 2. $4 \times 4 \mathrm{TU}$ mode decision process in HM.
정보이다. 따라서, $\mathrm{CBF}=1$ 인 $\mathrm{TU}$ 내에 적어도 하나 이 상의 0 이 아닌 양자화 값이 존재함과 양자화된 잔차 신호가 부호화 됨을 의미한다. 반대로 $\mathrm{CBF}$ 가 0 으로 설정된 경우는 전송될 양자화 값이 모두 0 임을 의미 하므로, $\mathrm{CBF}$ 를 제외한 잔차신호 정보는 부호화 되지 않는다. 상기 언급한 $\mathrm{HM}$ 의 변환생략 모드 결정방법 을 사용하는 경우, 변환생략을 전혀 사용하지 않는 경 우와 비교하여 영상에 따라 최대 $15.21 \%$ 의 율-왜곡 성능이 향상되며 평균적으로 $7.93 \%$ 의 전체 부호화기 복잡도가 증가한다. 구체적인 변환생략 모드에 대한 부호화 효율 및 복잡도 측면의 분석은 4장에서 설명 한다.

\section{III. 제안하는 변환생략 모드 고속 선택 방법}

\section{1 변환생략 모드의 통계적 특성 분석}

효율적인 고속 부호화기 구현을 위한 가장 기본적 인 방안은, 최종 부호화 모드로 선택될 가능성이 높은 모드 위주로 먼저 최적 여부를 따져, 소정의 조건을 만족하는 경우 조기에 모드결정을 완료하는 것이다. 이런 측면을 검토하기 위하여 $4 \times 4 \mathrm{TU}$ 의 모드 선택 과정에서 변환생략 모드가 최적 모드로 최종 결정될 확률을 분석하였다. 표 1 은 부호화기가 수행하는 모드 선택 과정에서 변환생략 모드가 최적 모드로 결정될 확률을 나타낸다. Class C는 $832 \times 480$ 크기의 일반 영 상으로서 BasketballDrill, BQMall, PartyScene, 그리 고 RaceHorses 실험 영상을 포함한다. 스크린 콘텐츠 인 Class F에는 BasketballDrillText, ChinaSpeed, SlideEditing, 그리고 SlideShow가 포함된다. 표 1에서 볼 수 있듯이 $4 \times 4 \mathrm{TU}$ 의 모드 선택과정에서 Class C 와 Class F 모두, 변환생략 모드가 선택될 확률은 상당 히 낮다 $(5 \%$ 미만). 따라서 변환 모드 결정에 필요한 연산을 먼저 수행한 후, 필요한 경우에 한하여 변환생 략 유무를 판별하는 것이, 그 반대인 변환생략 모드에 필요한 연산을 우선적으로 수행하는 것과 비교해, 더 효율적인 복잡도 감소를 가져올 수 있다.

표 1. $4 \times 4 \mathrm{TU}$ 의 모드 선택과정에서 변환생략 모드가 최 종 선택될 확률 $(\%)$

Table 1. Probability of transform skip mode selected by $4 \times 4$ TU mode decision process (\%).

\begin{tabular}{c|c|c|c|c}
\hline \multirow{2}{*}{ Sequence } & \multicolumn{4}{|c}{ QP } \\
\cline { 2 - 5 } & 22 & 27 & 32 & 37 \\
\hline Class C & 5.2 & 2.1 & 0.9 & 0.2 \\
\hline Class F & 3.5 & 2.3 & 1.4 & 0.8 \\
\hline Avg. & 4.4 & 2.2 & 1.2 & 0.5 \\
\hline
\end{tabular}


일반적으로 영상의 부호화 시 공간 영역의 잔차신 호를 변환을 통해 에너지가 집중된 주파수 영역에서 부호화함으로써 부호화 효율을 극대화 시킬 수 있다. 하지만 잔차신호에 고주파 성분이 많이 존재하는 경 우, 변환으로 인해 공간영역의 에너지가 주파수 영역 에서는 더욱 분산되는 경우가 발생한다. 이는 향후 런 길이 (run length) 부호화와 같은 엔트로피부호화를 고려할 때, 변환을 수행하는 것이 오히려 부호화 효율 을 저하시킬 수 있다. 이를 고려하면 에너지 집중 정 도를 고려하여 변환생략 모드의 사용필요 여부를 유 추할 수 있다. 본 논문은 양자화 된 신호의 last coefficient index (양자화 후 0이 아닌 coefficient의 index 중 가장 큰 index)를 기반으로 에너지 집중 정 도를 판별한다. $\mathrm{HEVC}$ 는 양자화된 잔차신호의 부호화 를 위해 3 가지 스캔 순서 (scan order)를 정의하고 있 다. 즉, 화면 간 예측 시에는 diagonal scan을 사용하 고, 화면 내 예측 시에는 예측 방향에 따라 diagonal scan, horizontal scan, 또는 vertical scan을 사용한다. 각 스캔 순서에 따라 $\mathrm{TU}$ 블록 내의 최 좌측 상단 위 치(변환을 사용한 경우 DC 위치, index=1에 해당)에 근접할수록 낮은 index를 배정하고, 우측 하단 위치 (변환을 사용한 경우 가장 고주파 위치; 최우측하단 index=16)로 갈수록 높은 index를 할당한다. 따라서 last coefficient index값이 작다면 변환에 의한 에너지 집중 정도가 크다고 판단할 수 있다. 또한, 반대로 last coefficient index가 크다면 에너지 집중 효율이 떨어 진다고 판단할 수 있다. 그림 3은 이를 확인하기 위하 여 측정한 last coefficient index 별로 변환생략 모드 가 $4 \times 4 \mathrm{TU}$ 의 최종 부호화 모드로 선택될 확률을 나 타낸다 (표 2의 영상시퀀스를 사용함). 한편, 잔차신호 정보가 부호화 되지 않는 $\mathrm{CBF}=0$ 의 경우는 index $=0$ 으로 배정하였다. 그림 3에서 확인할 수 있듯이 last

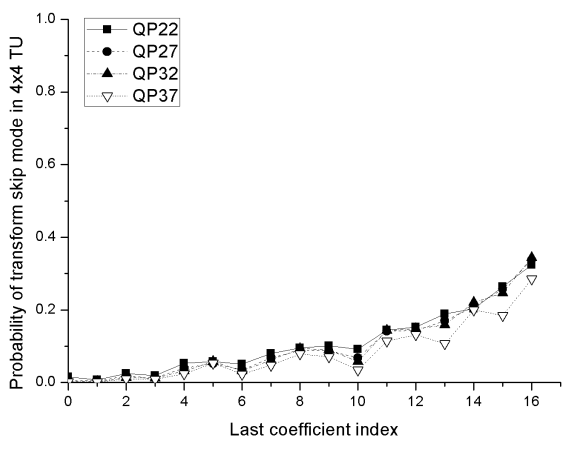

(a) Class $\mathrm{C}$ coefficient index가 증가할수록 변환생략 모드가 선택 될 확률 또한 증가한다. 따라서 last coefficient index 를 변환생략 여부의 판단 근거로 활용할 수 있음을 알 수 있다.

\section{2 제안 방법}

앞서 분석한 변환생략 모드의 발생특성을 기반으로 본 논문에서는 그림 4 와 같은 변환생략 모드 고속 선 택방법을 제안한다. 제안하는 방법은, 표 1에 나타난 바와 같이 변환 모드가 최종적으로 선정될 확률이 매 우 크므로, 먼저 변환을 수행한 후, 변환생략 모드가 부호화 효율면에서 더 유리할 가능성이 있는지 여부 를 검토하여, 더 유리할 가능성이 있는 경우에 한하여 변환생략 모드에 대한 율-왜곡 비용을 추가로 계산한 다. 이렇게 하면, 변환생략 기술을 전혀 쓰지 않는 간 단한 방법에 대비하여 증가되는 연산복잡도를 최소화 시키면서도 변환생략 기술을 사용할 수 있는 장점이 있다.

변환생략 모드가 부호화 효율면에서 더 유리할 가 능성이 있는지 여부는, 변환을 수행한 잔차신호의

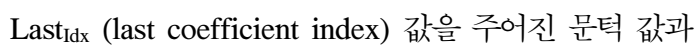
비교하도록 하여, 변환 후 잔차신호의 에너지 집중도 정도를 판별한다. 만약 Last $_{\mathrm{Idx}}$ 가 미리 정의된 문턱 값 $\left(\mathrm{Thr}_{\mathrm{Idx}}\right)$ 보다 작은 경우는 변환을 수행한 후 고주파 성 분이 많이 존재하지 않으므로 변환을 통한 에너지 집 중도가 우수함을 의미한다. 그러므로 변환생략 모드가 최종 선택될 확률은 매우 작다. 따라서, 이 경우는 $4 \times 4 \mathrm{TU}$ 의 모드의 후보군에서 변환생략 모드를 더 이상 고려하지 않고, 변환을 수행하는 모드로 즉시 결 정한다. 표 1 을 참조하면 대부분의 $\mathrm{TU}$ 에서 이와 같은 결정이 내려질 것임이 예상된다. 한편, 반대로 $\mathrm{Last}_{\mathrm{Idx}}$ 가 $\mathrm{Thr}_{\mathrm{Idx}}$ 보다 큰 경우는, 어느 정도 이상의 고주파

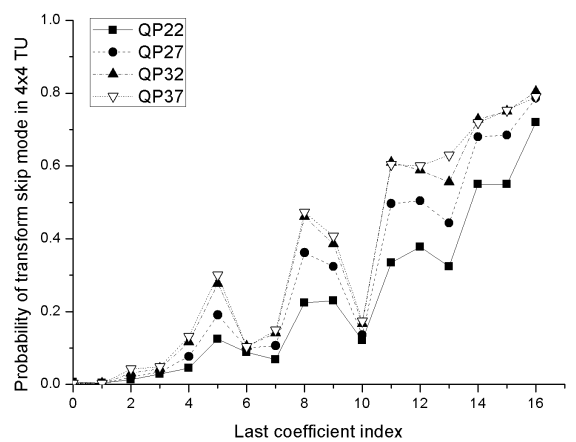

(b) Class $\mathrm{F}$

그림 3. Last coefficient index에 따른 변환생략 모드 최종 선택 확률 (\%)

Fig. 3. Probability (in \%) of selecting the transform skip mode according to last coefficient index. 


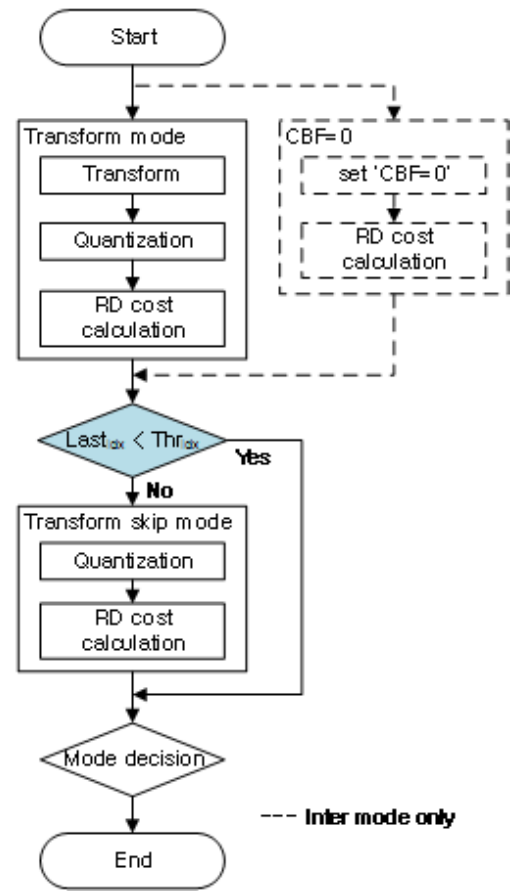

그림 4. 제안하는 변환생략 모드 고속 선택 방법

Fig. 4. Proposed transform skip mode fast decision method.

성분이 존재하며 변환을 통한 에너지 집중도 정도가 미미하거나 오히려 더 악화된 경우를 의미할 수 있으 므로, 변환생략 모드가 부호화 효율면에서 더욱 우수 할 수 있다는 가능성을 시사한다. 따라서, 이 경우 변 환생략 모드에 대한 율-왜곡 비용을 추가로 계산하여 변환 모드의 경우와 비교하는 과정을 수행한다.

\section{$\mathrm{IV}$. 실험 결과 및 분석}

제안 방법의 성능을 평가하기 위하여 $\mathrm{HEVC}$ 참조 소프트웨어 HM $11.0^{[7]}$ 에 제안 방법을 구현하였다. 본 실험에서는 앞서 3.2절에서 언급한 제안 방법에서 사 용하는 문턱 값인 $\mathrm{Thr}_{\mathrm{Idx}}$ 값을 설정하기 위하여 표 2의 Class F 영상들을 사용하였다. 변환생략 모드의 사용 유무에 따른 부호화 성능 차이는 Class F에서 특히 두 드러진다. 따라서 실험적으로 Class F에서 부호화 성 능 감소 대비 가장 적절한 복잡도 감소를 보이는 index 4 를 문턱 값으로 결정하였다. 즉, 본 논문의 실 험에서는 Last $\mathrm{Idx}_{\mathrm{dx}}$ 가 index 4 미만인 경우 변환생략 모 드를 고려하지 않게 된다. 제안 방법의 부호화 성능은 BDBR (Bjøntegaard delta bit rate) ${ }^{[8]}$ 과, BDPSNR (Bjøntegaard delta peak signal to noise ratio) ${ }^{[8]}$ 을 사 용하여 평가하였고 복잡도 감소를 측정하기 위하여
다음의 수식 (1)을 사용하였다.

$$
A S T=\frac{T_{E n c}(\text { Anchor })-T_{E n c}(\text { Method })}{T_{E n c}(\text { Anchor })} \times 100[\%]
$$

수식 (1)의 AST (Average Saving Time)는 평균 부호화시간 감소를 의미하고 $\mathrm{T}_{\mathrm{Enc}}(\cdot)$ 는 Anchor 와 본 논문의 제안 방법 중 해당 방법의 부호화 시간을 의미 한다. 여기서 Anchor는 HM 11.0에서 변환생략모드 를 활성화 (transform skip mode enable) 시킨 후 부 호화하는 것으로써, 부호화기는 각 TU별로 변환 모드 와 변환 생략모드 중에서 율-왜곡 측면에서 더 효율적 인 하나를 선택하여 부호화 한다. 이 방법은 부호화 효율면에서는 가장 유리하나 부호화를 위한 연산복잡 도가 가장 큰 경우에 해당한다. 실험 조건은 JCT-VC 에서 권고한 common test condition ${ }^{[9]}$ 를 준수하였고 각 실험 영상별로 100 frame 을 부호화 하였다. 제안 방법과의 성능 비교를 위하여 변환생략을 전혀 사용 하지 않는 방법 (TSM off)을 비교방법에 포함하였다. 구체적 실험조건은 표 2와 같다. 표 3과 표 4는 TSM off 방법과 제안 방법을 각각 Anchor에 대하여 부호 화 효율 측면의 성능 및 복잡도 감소를 측정한 결과이 다. 표 3에서 확인할 수 있듯이 변환생략을 전혀 사용 하지 않는 경우 (즉, TSM off 방법의 경우), 자연 영 상인 Class B, C에서는 Anchor대비 부호화 효율의 변 화가 거의 눈에 띄지 않으나, 스크린 콘텐츠인 Class

\section{표 2. 실험 조건}

Table 2. Experimental condition.

\begin{tabular}{l|l|l}
\hline \multirow{4}{*}{ Test sequence } & Class B & $\begin{array}{l}\text { Kimono, ParkScene, } \\
\text { Cactus, BasketballDrive, } \\
\text { BQTerrace }\end{array}$ \\
\cline { 2 - 3 } & Class C & $\begin{array}{l}\text { BasketballDrill, BQMall, } \\
\text { PartyScene, RaceHorses }\end{array}$ \\
\cline { 2 - 3 } GOP structure & $\begin{array}{l}\text { BasketballDrillText, } \\
\text { Class F } \\
\text { CainaSpeed, SlideEditing, } \\
\text { SlideShow }\end{array}$ \\
\hline Tested frames & \begin{tabular}{l} 
100 frames \\
\hline \multirow{3}{*}{ Comparison }
\end{tabular} & $\begin{array}{l}\text { Anchor - HM 11.0 } \\
\text { (transform skip mode enable) }\end{array}$ \\
\cline { 2 - 3 } & $\begin{array}{l}\text { TSM off - HM 11.0 } \\
\text { (transform skip mode disable) }\end{array}$ \\
\cline { 2 - 3 } & $\begin{array}{l}\text { Proposed - HM 11.0 } \\
\text { (proposed transform skip mode } \\
\text { decision method) }\end{array}$ \\
\hline
\end{tabular}


표 3. 부호화 효율 비교

Table 3. Comparison of coding efficiency.

\begin{tabular}{|c|c|c|c|c|c|c|c|c|c|c|c|c|c|}
\hline \multirow{3}{*}{\multicolumn{2}{|c|}{ Test sequence }} & \multicolumn{4}{|c|}{ All intra (AI) } & \multicolumn{4}{|c|}{ Random access (RA) } & \multicolumn{4}{|c|}{ Low delay (LD) } \\
\hline & & \multicolumn{2}{|c|}{ TSM off } & \multicolumn{2}{|c|}{ Proposed } & \multicolumn{2}{|c|}{ TSM off } & \multicolumn{2}{|c|}{ Proposed } & \multicolumn{2}{|c|}{ TSM off } & \multicolumn{2}{|c|}{ Proposed } \\
\hline & & $\begin{array}{c}\text { BDBR } \\
{[\%]}\end{array}$ & $\begin{array}{c}\text { BD- } \\
\text { PSNR } \\
{[\mathrm{dB}]}\end{array}$ & $\begin{array}{c}\text { BDBR } \\
{[\%]}\end{array}$ & $\begin{array}{c}\text { BD- } \\
\text { PSNR } \\
{[\mathrm{dB}]}\end{array}$ & $\begin{array}{c}\text { BDBR } \\
{[\%]}\end{array}$ & $\begin{array}{l}\text { BD- } \\
\text { PSNR } \\
{[\mathrm{dB}]}\end{array}$ & $\begin{array}{c}\text { BDBR } \\
{[\%]}\end{array}$ & $\begin{array}{l}\text { BD- } \\
\text { PSNR } \\
{[\mathrm{dB}]}\end{array}$ & $\begin{array}{c}\text { BDBR } \\
{[\%]}\end{array}$ & $\begin{array}{c}\text { BD- } \\
\text { PSNR } \\
{[\mathrm{dB}]} \\
\end{array}$ & $\begin{array}{c}\text { BDBR } \\
{[\%]}\end{array}$ & $\begin{array}{c}\text { BD- } \\
\text { PSNR } \\
{[\mathrm{dB}]}\end{array}$ \\
\hline \multirow{5}{*}{ Class B } & Kimono & -0.01 & 0.00 & 0.00 & 0.00 & 0.05 & 0.00 & 0.00 & 0.00 & 0.07 & 0.00 & -0.07 & 0.00 \\
\hline & ParkScene & -0.01 & 0.00 & 0.01 & 0.00 & 0.00 & 0.00 & -0.03 & 0.00 & -0.04 & 0.00 & -0.08 & 0.00 \\
\hline & Cactus & -0.02 & 0.00 & 0.01 & 0.00 & 0.03 & 0.00 & -0.06 & 0.00 & -0.05 & 0.00 & 0.06 & 0.00 \\
\hline & BasketballDrive & -0.01 & 0.00 & 0.01 & 0.00 & -0.16 & 0.00 & -0.23 & 0.00 & -0.07 & 0.00 & -0.07 & 0.00 \\
\hline & BQTerrace & -0.01 & 0.00 & 0.01 & 0.00 & 0.10 & 0.00 & 0.01 & 0.00 & 0.11 & 0.00 & -0.02 & 0.00 \\
\hline \multirow{4}{*}{ Class $\mathrm{C}$} & BasketballDrill & 0.06 & 0.00 & 0.04 & 0.00 & 0.18 & -0.01 & 0.18 & -0.01 & 0.50 & -0.02 & 0.24 & -0.01 \\
\hline & BQMall & 0.05 & 0.00 & 0.03 & 0.00 & 0.20 & -0.01 & 0.08 & 0.00 & 0.30 & -0.01 & 0.02 & 0.00 \\
\hline & PartyScene & 0.25 & -0.02 & 0.02 & 0.00 & 0.57 & -0.03 & 0.14 & -0.01 & 0.60 & -0.03 & 0.18 & -0.01 \\
\hline & RaceHorses & -0.03 & 0.00 & -0.01 & 0.00 & 0.03 & 0.00 & 0.06 & 0.00 & 0.11 & 0.00 & 0.01 & 0.00 \\
\hline \multirow{4}{*}{ Class $\mathrm{F}$} & BasketballDrillText & 0.29 & -0.02 & 0.03 & 0.00 & 0.32 & -0.01 & -0.01 & 0.00 & 0.51 & -0.02 & 0.19 & -0.01 \\
\hline & ChinaSpeed & 12.83 & -1.13 & 0.13 & -0.01 & 14.56 & -0.78 & 0.96 & -0.06 & 13.69 & -0.71 & 0.38 & -0.02 \\
\hline & SlideEditing & 15.21 & -2.25 & -0.14 & 0.02 & 13.11 & -1.95 & -0.50 & 0.08 & 11.35 & -1.68 & -0.45 & 0.07 \\
\hline & SlideShow & 3.39 & -0.30 & 0.16 & -0.01 & 5.11 & -0.41 & -0.10 & 0.01 & 4.77 & -0.33 & -0.06 & 0.00 \\
\hline \multicolumn{2}{|c|}{ Avg. of Class B, C } & 0.03 & 0.00 & 0.01 & 0.00 & 0.11 & 0.00 & 0.02 & 0.00 & 0.17 & 0.00 & 0.03 & 0.00 \\
\hline \multicolumn{2}{|c|}{ Avg. of Class $\mathrm{F}$} & 7.93 & -0.93 & 0.04 & 0.00 & 8.27 & -0.79 & 0.09 & 0.01 & 7.58 & -0.69 & 0.01 & 0.01 \\
\hline \multicolumn{2}{|c|}{ Avg. of total } & 2.67 & -0.29 & 0.02 & 0.00 & 2.84 & -0.25 & 0.04 & 0.00 & 2.64 & -0.22 & 0.03 & 0.00 \\
\hline
\end{tabular}

표 4. 부호화 복잡도 감소 측면의 비교

Table 4. Comparison of encoding complexity reduction.

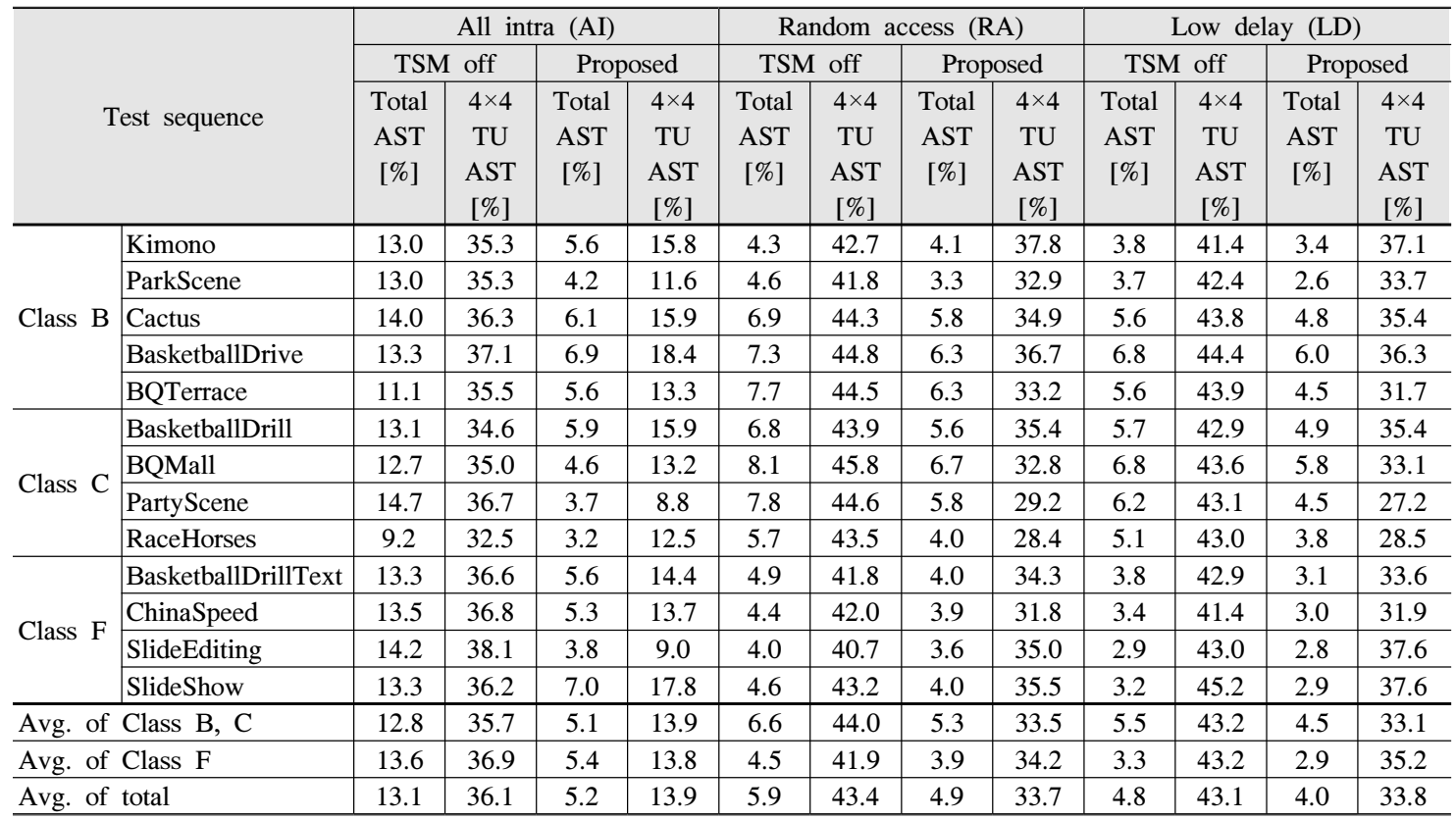

$\mathrm{F}$ 에서는 평균 $7.93 \%$ 정도 압축성능이 감소하는 것을 볼 수 있다. HEVC 표준을 위하여 고려된 많은 기술 들의 압축 성능 개선정도가 $1 \%$ 내외의 것들도 많았던 것을 감안하면 약 $8 \%$ 에 달하는 압축성능의 감소는 매
우 큰 수치이다. 즉, TSM off를 통하여 변환생략 모드 자체를 사용하지 않는 경우는, 스크린 콘텐츠를 다루 는 경우 압축성능에서 많은 손해를 볼 수 있음을 시사 한다. 한편, 부호화기의 연산복잡도 측면으로 볼 때, 
TSM off 경우의 Anchor 대비 부호화 복잡도 감소량 은 $\mathrm{AI}$ 의 경우 $4 \times 4 \mathrm{TU}$ 부호화 시간 기준 $36.1 \%$ (전 체 부호화 시간 기준 $13.1 \%$ )이고 $\mathrm{RA}$ 와 $\mathrm{LD}$ 의 경우 각각 $43.4 \%$ 와 $43.1 \%$ (전체 부호화 시간 기준 $5.9 \%$ 와 $4.8 \%$ ) 이다. 이는 변환생략 기능을 사용하는 Anchor 대비, 고속 변환생략 방법으로 인해 절약될 수 있는 복잡도 감소의 최대 한계를 나타낸다.

제안 방법의 경우 Class B, C에서 부호화 효율 열 화가 거의 발견되지 않았다. 또한 Class F에서는 평균 적으로 약 $0.05 \%$ 의 부호화 효율 감소를 보였고 Class $\mathrm{B}, \mathrm{C}, \mathrm{F}$ 전체에 대한 평균적인 부호화 효율 감소량은 $0.03 \%$ 이다. Anchor 대비 제안 방법의 복잡도 감소량 은 $4 \times 4 \mathrm{TU}$ 부호화 시간 기준으로 $\mathrm{AI}$ 에서는 $13.9 \%$ 이고 $\mathrm{RA}, \mathrm{LD}$ 각각 $33.7 \%, 33.8 \%$ 이다. 그리고 전체 부호화 시간을 기준으로 보면 각각 $5.2 \%, 4.9 \%, 4.0 \%$ 이다. 앞서 언급한 복잡도 감소의 최대 한계치를 기준 으로 할 때, 제안 방법의 변환생략 간략화 달성률 ( $R_{\text {Achieve }}$ )은 식 (2)를 사용하여 산출 할 수 있다.

$$
R_{\text {Achieve }}=\frac{A S T \text { (proposed })}{A S T(\text { TSMoff })} \times 100[\%]
$$

$R_{\text {Achieve }}$ 는 $4 \times 4 \mathrm{TU}$ 부호화 시간 기준으로 $\mathrm{AI}$ 의 경 우 $38.5 \%$ 이고, $\mathrm{RA}, \mathrm{LD}$ 각각 $77.6 \%, 78.4 \%$ (AI, $\mathrm{RA}, \mathrm{LD}$ 전체의 평균은 $64.8 \%)$ 이다. 그리고 전체 부 호화 시간 기준으로는 각각 $39.7 \%, 83.1 \%, 83.3 \%$ (AI, RA, LD 전체의 평균은 $68.7 \%$ )이다.

실험 결과를 통해 제안 방법의 복잡도 감소 측면의 성능이 $\mathrm{AI}$ 에서보다 $\mathrm{RA}$ 와 $\mathrm{LD}$ 에서 우수한 것으로 나 타났다. 따라서 화면 내 예측 (AI는 모든 frame을 화 면 내 예측 부호화 수행)보다 화면 간 예측 (RA와 LD 는 대부분의 frame이 화면 간 예측 부호화 수행)에서 제안 방법에 의한 복잡도 감소량이 크다고 할 수 있 다. 이는 제안방법에 의해 변환생략 모드를 고려하지 않게 된 경우 (즉, Last $_{\mathrm{dx}}$ 가 index 4 미만인 경우)가 화면 간 예측에서 화면 내 예측보다 빈번하게 발생함 을 의미한다. 이러한 차이는 화면 간 예측과 화면 내 예측의 예측 성능 차이에 기인한 것으로, 일반적으로 화면 간 예측의 경우 화면 내 예측의 경우보다 상대적 으로 적은 에너지의 잔차신호를 생성함은 널리 알려 진 사실이다. 따라서 화면 간 예측 시, Last $_{\mathrm{Idx}}$ 가 index 4 미만인 경우가 발생할 확률이 상대적으로 높을 것 임을 예상할 수 있다.

\section{V. 결 론}

본 논문에서는 저복잡도 $\mathrm{HEVC}$ 부호화기 구현을 위한 변환생략 모드 고속 선택 방법을 제안하였다. 변 환생략 모드의 통계적 특성을 분석하였고 이를 기반 으로 제안한 방법은 변환 및 양자화 처리된 잔차신호 의 에너지 집중도 정도를 판별하여 변환생략의 율-왜 곡 산출 여부를 고속으로 결정한다. 이때 에너지 집중 도 정도의 판별을 위하여 잔차신호의 last coefficient index를 참조한다. 제안 방법이 율-왜곡 비용 비교를 통하여 변환생략 모드를 선택하는 기존의 방법과 비 교하여 부호화 효율 변화에 주는 영향은 매우 미미한 반면 $4 \times 4 \mathrm{TU}$ 부호화 시간 기준 평균 $27.1 \%$ 의 복잡 도를 감소시킴을 실험을 통하여 확인하였다.

\section{References}

[1] ITU-T and ISO/IEC JTC 1, High efficiency video coding, ITU-T Rec. H.265 and ISO/IEC 23008-2, Apr. 2013.

[2] ITU-T and ISO/IEC JTC 1, Advanced video coding for generic audio-visual services, ITU-T Rec. H.264 and ISO/IEC 14496-10 (AVC), May 2003 (and subsequent editions).

[3] C. Lan, J. Xu, G. J. Sullivan, and F. Wu, "Intra transform skipping," JCTVC-I0408, JCT-VC, Geneva, Switzerland, Apr. 2012.

[4] X. Peng, C. Lan, J. Xu, and G. J. Sullivan, "Inter transform skipping," JCTVC-J0237, JCT-VC, Stockholm, Sweden, Jul. 2012.

[5] D. Flynn, M. Naccari, K. Sharman, C. Rosewarne, J. Sole, G. J. Sullivan, and T. Suzuki, "High efficiency video coding (HEVC) range extensions text specification: Draft 6," JCTVC-P1005, JCT-VC, San Jose, USA, Jan. 2014.

[6] C. Y. Park, "The development of the fast algorithms for the DCT, DST and DHT," $J$. KICS, vol. 12, no. 3, pp. 239-253, Jun. 1987.

[7] JCT-VC HEVC reference S/W version HM 1 1.0, available online at https://hevc.hhi.fraunho fer.de/svn/svn_HEVCSoftware/tags/HM-11.0.

[8] G. Bjontegaard, "Calculation of average PSNR differences between RD-curves," VCEG-M33, ITU-T Video Coding Experts Group (VCEG) 
Meeting, Austin, TX, Apr. 2-4, 2001.

[9] Frank Bossen, "Common test conditions and software reference configurations," JCTVCL1100, JCT-VC, Geneva, Switzerland, Jan. 2013.

양 승 하 (Seungha Yang)

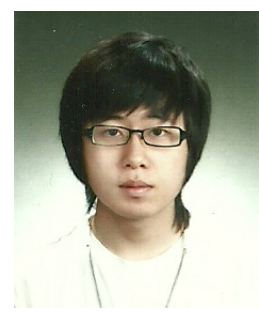

2013년 : 성균관대학교 정보통 신대학 졸업 (학사)

2013년 현재 : 성균관대학교 정 보통신대학 석사과정

<관심분야> 멀티미디어 영상압 축, 신호처리

심 혁 재 (Hiuk Jae Shim)

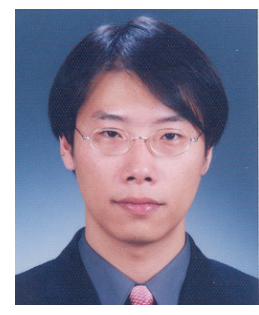

2000년 : 성균관대학교 전자공 학과 졸업 (학사)

2002년 : 성균관대학교 정보통

신공학부 졸업 (석사)

2013년 : 성균관대학교 정보통

신공학부 졸업 (공학박사)

<관심분야> 멀티미디어 영상압

축, 신호처리
이 다 희 (Dahee Lee)

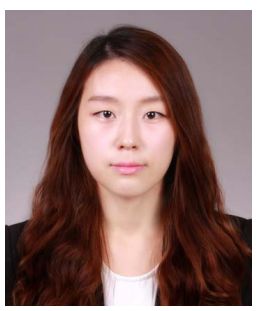

2014년 : 성균관대학교 정보통 신대학 졸업 (학사)

2014년 현재 : 성균관대학교 정보통신대학 석사과정 <관심분야> 멀티미디어 영상압 축, 신호처리

전 병 우 (Byeungwoo Jeon)

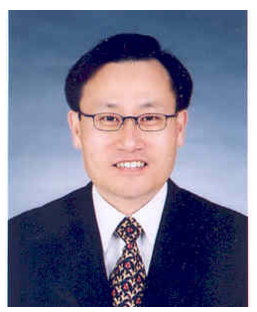

1985년 : 서울대학교 전자공학 과 졸업 (학사)

1987년 : 서울대학교 전자공학 과 졸업 (석사)

1992년 : Purdue Univ, School of Elec. 졸업 (공학박사) <관심분야> 멀티미디어 영상압 축, 영상인식, 신호처리 